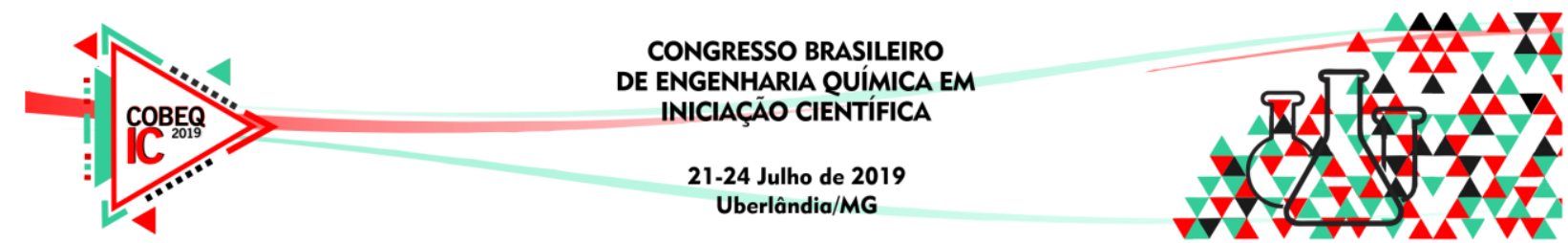

\title{
DESENVOLVIMENTO DE EMPANADOS APLICANDO CARNE DO DORSO DE RÃ TOURO ENRIQUECIDOS COM FIBRAS
}

\author{
M. D. D. OLIVEIRA ${ }^{1}$, V. C. R. SCHMIDT ${ }^{1}$ \\ ${ }^{1}$ Universidade Federal de Uberlândia, Discente da Faculdade de Engenharia Química \\ E-mail: mayconoliveira150@ outlook.com
}

\begin{abstract}
RESUMO - A ranicultura ainda não possui muito espaço no mercado, devido o interesse comercial somente nas suas coxas, consequentemente, não ocorrendo uma demanda em larga escala para sua produção. Assim este trabalho baseou em apresentar uma alternativa para a ranicultura, por demonstrar ser uma cultura que possui um grande potencial, no interesse em ocasionar novos estudos e produtos oriundos da carne de rã-touro. Neste contexto, o objetivo do projeto foi a preparo de empanados com aplicação de fibras, para contribuírem em propriedades reológicas, além de fornecer características mais nutritivas aos comercializados atualmente. Foram testados 3\% de fibras (Gergelim, Linhaça e Proteína Texturizada de soja). As características sensoriais foram avaliadas com intuito de verificar o grau de aceitabilidade do público consumidor, e a identificação de parâmetros físicos, como textura e cor. Os resultados obtidos demonstraram que o produto adquiriu características próximas ao empanado de rã sem fibras, resultando em uma ótima aceitabilidade do produto final. Portanto, o empanado de rã enriquecidos com fibra torna se uma alternativa com potencial de vendas no mercado e na agregação de valor as perdas durante sua produção.
\end{abstract}

\section{INTRODUÇÃO}

O sistema de produção industrial vem despertando atenção entre governantes, técnicos e produtores para mudanças significativas nos mais variados segmentos de carne e seus derivados, procurando desenvolver alimentos saborosos, que apresentem baixo preço, reaproveitamento e elevado valor nutricional. Diante disso, a ranicultura é uma área que vem se aperfeiçoando dentro desses segmentos, sendo que a carne comercializada é obtida através do abate da rã-touro, Rana catesbeiana (Lawrie, 2005).

Atualmente, estima-se que a quantidade de carne de rã-touro abatida está em um total de 700 toneladas/ano (Aquicultura Brasileira, 2018), sendo preferida para o consumo as patas (coxas) ou sua carcaça inteira congelada, ocorrendo consequentemente o descarte da parte dorsal da carcaça da rã. Sua carne apresenta excelente qualidade nutricional e possui um adequado balanceamento de aminoácidos e baixo percentual de lipídeos (Feix et al. 2006). De acordo com Mello et al. (2006), os resultados de análises físico-químicas das carnes de dorso e coxa de rã foram respectivamente: $\mathrm{pH}(6,3$ e 6,0$)$, proteína $(16 \%$ e $15,7 \%)$, lipídios $(0,2 \%$ e $0,2 \%)$, umidade $(79,2 \%$ e $78,3 \%)$, cinzas $(1,2 \%$ e $0,9 \%)$, cálcio $(0,09$ e $0,05 \%)$. 


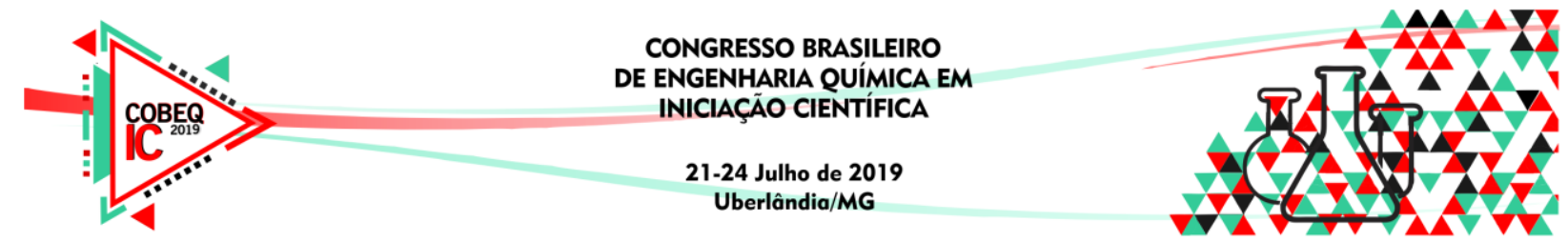

A aplicação de fibras alimentares nos empanados consiste nos efeitos positivos causados após sua ingestão no organismo como a redução dos níveis séricos de colesterol, melhora da glicemia em pacientes com diabetes e a redução do peso corporal. Além disso, as fibras também colaboram para as propriedades reológicas de produtos (Mudgil e Barak, 2013) através de características como a solubilidade, viscosidade, formação de gel, capacidade de retenção de água e aumento de volume através de associação entre moléculas (Cummings e Stephen, 2007; Mudgil e Barak, 2013). Dentre essas propriedades, a solubilidade das fibras é relevante, principalmente, por definir os efeitos tecnológicos e fisiológicos dos alimentos (Elleuch et al., 2011).

Com isso, devido aos poucos estudos científicos relativos à carne de rã-touro e seus derivados, este trabalho objetivou desenvolver um produto alimentício, empanados, com a utilização de partes que não possui grande procura ou sem valor comercial para vendas diretas no mercado, como o dorso da rã, além de melhorar seus aspectos nutritivos e sensoriais com aplicação de fibras, seguindo como pré-requisito o estudo de métodos científicos acadêmicos. Visando assim trazer a valorização das perdas através de subprodutos e resultando na melhoria da economia brasileira, dentro deste novo segmento.

\section{MATERIAIS E METODOS}

\subsection{Processamento de Empanados}

O projeto foi realizado pela Universidade Federal de Uberlândia (UFU), dentro do curso de Engenharia de Alimentos, nos laboratórios de análises de alimentos, do Campus Patos de Minas. A matéria-prima para a elaboração dos empanados a carne da rã-touro (Rana catesbeiana) foi cedida pelo ranário situado na fazenda do campus Glória da Universidade Federal de Uberlândia, na cidade de Uberlândia. Os demais ingredientes para a sua elaboração (descritos na Tabela 1), foram adquiridos no mercado local em Patos de Minas.

Todo o processamento para a obtenção dos empanados seguiu a metodologia descrita por Oliveira e Schmidt (2017), no qual desenvolveu empanados aplicando carne do dorso da rã touro (Rana Catesbeianna). Durante a etapa de adição de fibras este trabalho se baseou no estudo já realizado por Beltrão (2012), no qual dentro dos 3\% de fibras presente na formulação, foram adicionados os seguintes teores com suas respectivas fibras, sendo 0,33\% de linhaça, 0,33\% de gergelim e 0,34\% de Proteína Texturizada de Soja - PTS e posteriormente adicionada na formulação. Após a obtenção de todas as unidades de empanados, as amostras foram seladas a vácuo e congeladas para as análises posteriores, onde pós essas análises as amostras serão comparadas com o produto padrão (empanados de rã porém com ausência de fibra).

\subsection{Análise de Cor}

Esta análise foi determinada usando-se o equipamento Colorímetro (CR400 MinoltaCompany). Sendo realizado três medições interna na parte cárnea do empanado de rã. As coordenadas $\mathrm{L}^{*} \mathrm{a} \mathrm{b}^{*}$ foram obtidas pelo espectro de reflexão das amostras utilizando iluminância $D 65 / 10^{\circ}$. No qual, neste sistema $L^{*}$ indica a luminosidade, a* indica a 


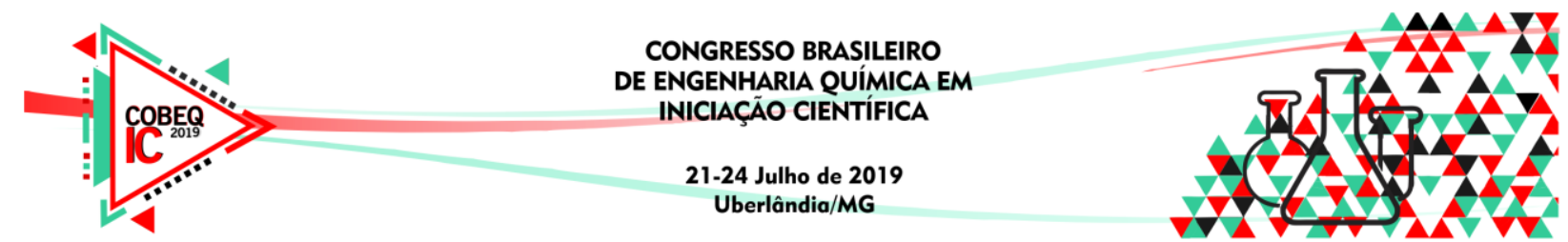

coordenada que varia do verde (-60) ao vermelho $(+60)$ e $b^{*}$ indica a coordenada que varia do azul (-60) ao amarelo (+60).

Tabela 1 - Formulação do empanado

\begin{tabular}{cc}
\hline Ingredientes & Quantidade (\%) \\
Carne de Rã & 63 \\
\hline Fibras & 3 \\
\hline Agua Gelada & 12,4 \\
\hline Amido de Milho & 1,88 \\
\hline Proteína Isolada de Soja & 3,76 \\
\hline Proteína Texturizada de Soja & 3,76 \\
\hline Cebola em pó & 1,81 \\
\hline Óleo de soja & 1,42 \\
\hline Alho em pó & 0,95 \\
\hline Condimento & 3,33 \\
\hline Glutamato de Sódio & 0,26 \\
\hline Maltodextrina & 2,42 \\
\hline Goma guar & 1,7 \\
\hline Goma Xantana & 0,31 \\
\hline Total & $\mathbf{1 0 0 \%}$ \\
\hline
\end{tabular}

Fonte: Próprio Autor.

\subsection{Análise de Textura}

Os parâmetros determinados foram dureza, coesividade, elasticidade e mastigabilidade, no qual a firmeza foi medida com uma força sobre a superfície da amostra (N) exercida para ruptura do tecido, utilizando uma probe em formato de disco. A profundidade de penetração utilizada foi $50 \%$ e a velocidade de teste foi $1 \mathrm{~mm} / \mathrm{s}$, utilizando um texturômetro (TAXTplus - Stable Micro Systems, Godalming, Inglaterra). O teste é destrutivo, sendo considerado representativo o número de 10 amostras.

\subsection{Análise Sensorial}

A análise sensorial consistiu em identificar a aceitação do produto desenvolvido no mercado. Para essa análise sensorial foi realizado um teste com um painel de julgadores não treinado, e a avaliação para aceitação do produto após a degustação consistiu no método de escala hedônica, onde dez pontos são distribuídos ao provador $(10=$ gostei muitíssimo, $5=$ indiferente, $1=$ desgostei muitíssimo). Os degustadores que avaliaram o desempenho do empanado inferiores a nota cinco, tiveram a possibilidade de apresentar críticas e sugestão para a melhoria deste produto. 


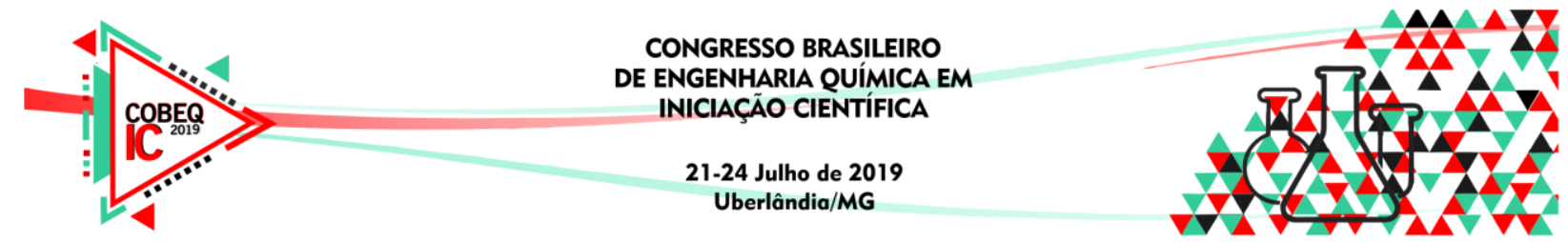

Juntamente com esta avaliação, foi realizado avaliação de intenção de compra pelos possíveis consumidores, no qual foi utilizada uma escala estruturada de cinco pontos (5=certamente compraria, $3=$ talvez comprasse/talvez não comprasse, $1=$ certamente não compraria).

\section{RESULTADO E DISCUSSÃO}

Estão apresentados na Tabela 2, os resultados das análises de textura e cor.

Analisando os dados referentes às análises de textura que constam na Tabela 2, os empanados de rã tiveram dureza semelhante, não apresentando diferença estatística em nível de 5\%. A elasticidade e mastigabilidade do empanado de rã com presença de fibras apresentaram redução destes parâmetros, mostrando que as fibras manteve a maciez ao produto.

Tabela 2 - Resultados das análises textura e de cor do empanado da carne de rã e frango.

\begin{tabular}{ccc}
\hline & Análise de Textura & \\
& $\begin{array}{c}\text { Empanado de Rã } \\
(\text { Ausência de Fibras) }\end{array}$ & $\begin{array}{c}\text { Empanado de Rã } \\
\text { (Presença de Fibras) }\end{array}$ \\
\hline Dureza (Kgf) & $11,41 \pm 2,40^{\mathrm{a}}$ & $10,76 \pm 1,76^{\mathrm{a}}$ \\
\hline Elasticidade (mm) & $4,90 \pm 0,48^{\mathrm{a}}$ & $3,94 \pm 0,09^{\mathrm{b}}$ \\
\hline Mastigabilidade (kgf*mm) $^{*}$ & $29,50 \pm 4,75^{\mathrm{a}}$ & $18,21 \pm 2,61^{\mathrm{b}}$ \\
\hline $\mathbf{L}^{*}$ & Análise de cor & $79.23 \pm 1.49^{\mathrm{a}}$ \\
\hline $\mathbf{b}^{*}$ & $81.05 \pm 0.41^{\mathrm{a}}$ & $1.32 \pm 0.25^{\mathrm{b}}$ \\
\hline As letras iguais na mesma linha não tiveram diferença significativa em nível de 5\%. & $0.32 \pm 0.14^{\mathrm{a}}$ \\
\hline & Fonte: Próprio Autor.
\end{tabular}

Interpretando os dados referente a análise de cor na Tabela 2, é possível notar que os parâmetro de luminosidade $\left(\mathrm{L}^{*}\right)$ e $\mathrm{b}^{*}$ apresentaram valores próximos referente aos empanados sem e com a presença de fibras, sendo possível afirmar que a presença de fibra (Linhaça, Gergelim e Proteína Texturizada de Soja - PTS) na formulação não apresentou diferença significativa quanto ao parâmetro cor, isso devido ao fato de que elas atuam diretamente nas propriedades reológicas do produto como o aumento da capacidade de retenção de água, incremento da estabilidade de emulsão, resultando em um produto com maior rendimento após cozimento (Choi, 2009; Mehta et al., 2013).

No parâmetro $a^{*}$ houve diferença significativa entre as amostras analisadas indicando uma tonalidade avermelha ao produto, porém acredita-se que a variação deste parâmetro está relacionado com devido ao processo de aquecimento dos carboidratos (Reação de Mailard), pois segundo o estudo realizado por Huber (2012), a adição de fibras ( $0,4 \%$ fibra de bambu, $1,6 \%$ fibra de trigo e 1,6\% fibra de ervilha) não promoveu alteração significativa nos parâmetros instrumentais de cor em empanados de frango.

O baixo teor de fibra presente na formulação não interfere quanto ao aspecto cor para este tipo produto, porém a concentração dos pigmentos presente na formulação podem interferir diretamente sobre esta característica do produto (LINDAHL et al., 2006). A Figura 1 apresenta os resultados referentes aos atributos da análise sensorial de aceitação. 


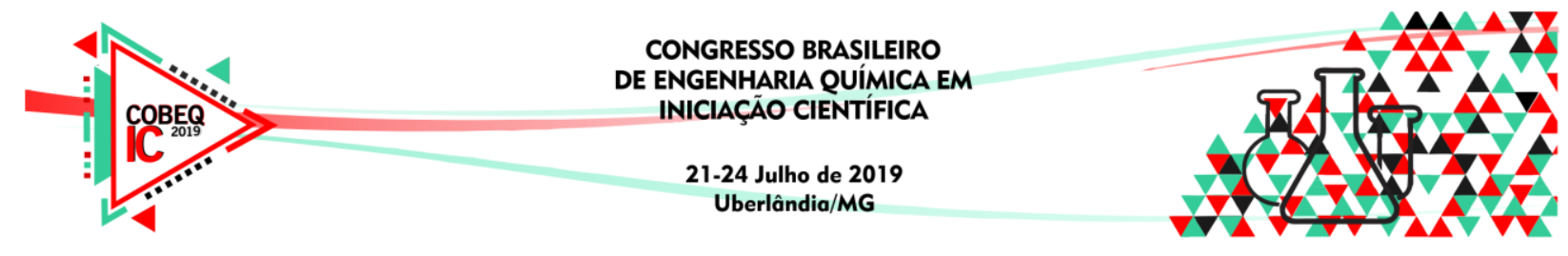

Os parâmetros de aceitabilidade estão divididos numa escala de menor aceitação até $30 \%$, neutros até $60 \%$ e o maior até $90 \%$. Com estes resultados podemos perceber que a faixa de 6 a 9, que corresponde a maior aceitação do produto foi a que obteve maiores notas (98\% - "Modo Geral"), assim percebe-se que a maioria dos participantes aprovaram o produto. Justificando essa informação nota-se que pela Figura 1 atributos como textura, aroma, sabor e modo geral teve valores de $88 \%, 98 \%, 100 \%$ e $98 \%$ respectivamente.

Figura 1 - Aceitabilidade.

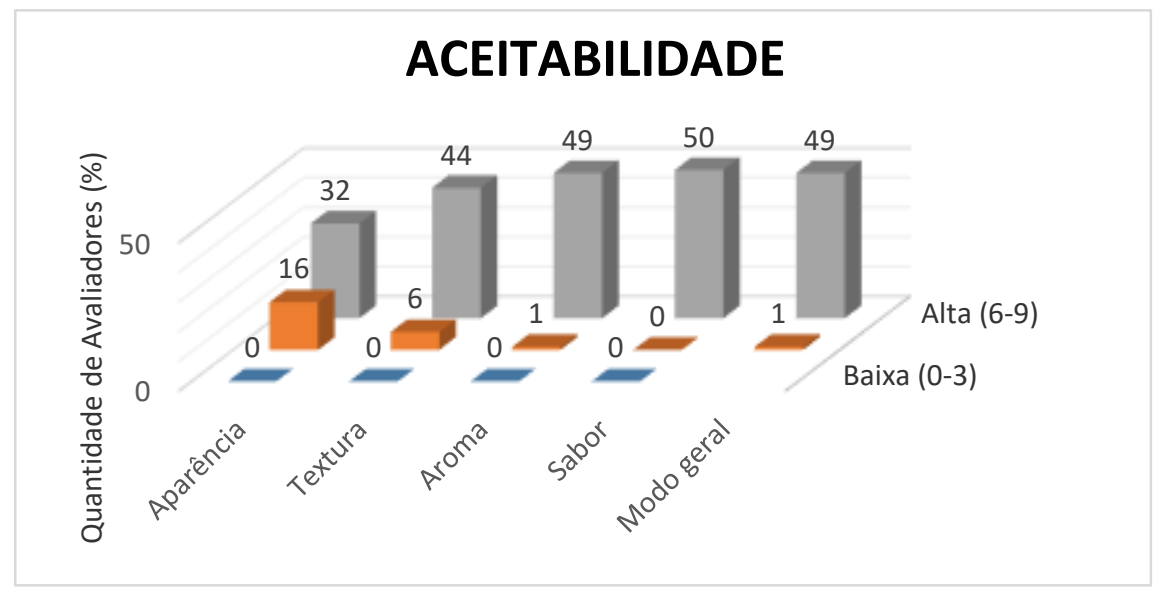

Fonte: Próprio Autor.

Nesse contexto, a Tabela 3 apresenta o teste de intenção de compra, onde é solicitado aos provadores se compraria ou não o produto, onde os atributos mais avaliados foram: certamente compraria, possivelmente compraria e talvez comprasse ou não produto.

Tabela 3 - Teste Intenção de Compra

\begin{tabular}{ll}
\hline Intenção de Compra & Quantidade (\%) \\
\hline Certamente Compraria & 54 \\
Possivelmente Compraria & 44 \\
Talvez Comprasse \ Não comprasse & 2 \\
\hline
\end{tabular}

Para os atributos certamente e possivelmente compraria, obteve-se resultados de $54 \%$ e $44 \%$ respectivamente e para o atributo se compraria ou não foi de $2 \%$. Isto está de acordo com os resultados apresentados anteriormente, no qual, o conceito modo geral $49 \%$ dos provadores qualificaram o produto com maior aceitação. Nos quesitos referentes a sabor, textura, aparência e aroma seus índices refletiram uma boa aceitabilidade do empanado de carne de rã pelos provadores, visto que o produto é considerado aceito sensorialmente quando o índice de aceitação é de $70 \%$ (Teixeira et al. 1987).

\section{CONCLUSÕES}

A obtenção da carne da carcaça de rã aplicada no desenvolvimento de derivados (empanados) enriquecidos com fibras, através das análises sensoriais e físicas, apresentaram 


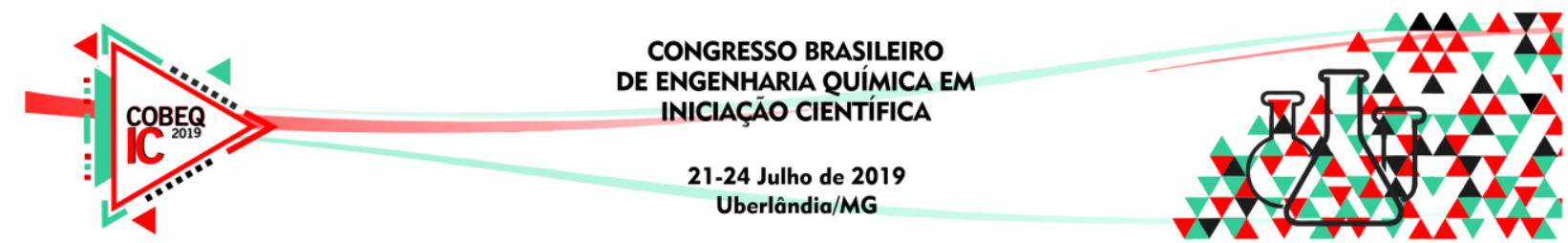

resultados satisfatórios e características próximas ao empanado de rã sem fibras, demonstrando assim uma possível aplicação no mercado com o objetivo de acarretar no aumento de sua produção e no consumo de carne de rã.

\section{AGRADECIMENTOS}

Os autores gostariam de agradecer ao CNPq, à CAPES, à FAPEMIG (Brasil), à Universidade Federal de Uberlândia, pelo apoio durante todo o trabalho.

\section{REFERENCIAS}

AQUICULTURA BRASILERIA. Disponível em: <www.brasil.gov.br/economia-eemprego/2015/06/aquicultura-tem-potencial-para-dobrar-producao-em-cinco-anos $>$

Acessado em 20 julho de 2018.

BELTRÃO. F.; FLORES, A. F. Desenvolvimento de Nuggets Enriquecidos com Fibras. Universidade Tecnológica do Paraná, Campus Francisco 2012.

CHOI, Y.S. Characteristics of low-fat meat emulsion systems with pork fat replaced by vegetable oils and rice bran fiber. Meat Science, v.82, p.266-271, 2009.

CUMMINGS, J.H.; STEPHEN, A.M. Carbohydrate terminology and classification. European Journal of Clinical Nutrition, v.61, S5-S18, 2007.

ELLEUCH, M. et al. Dietary fibre and fibre-rich by-products of food processing: Characterization, technological functionality and commercial applications: A review. Food Chemistry, v.124, p.411-421, 2011.

FEIX, R. D.; ABDALLAH, P. R.; FIGUEIREDO, M. R. C. Resultado econômico da criação de rã em regiões de clima temperado, Brasil. Informações Econômicas, SP, 2006.

HUBER, Eduardo. Desenvolvimento de produtos cárneos reestruturados de frango (hambúrguer e empanado) com adição de fibras vegetais. Universidade Federal de Santa Catarina - UFSC, Florianópolis/SC, 2012.

LAWRIE, R. A. Ciência da carne. 6. ed. Porto Alegre: Artmed, 2005.

LINDAHL, G.; KARLSSON, A.H.; LUNDSTRÖM, K.; ANDERSEN, H.J. Significance of storage time on degree of blooming and colour stability of pork loin from different crossbreeds. Meat Science, v.72, n.4, p. 603-612, 2006.

MEHTA, N. et al. Novel trends in development of dietary fiber rich meat products - a critical review. Journal of Food Science and Technology, p.1-15, 2013.

MUDGIL, D.; BARAK, S. Composition, properties and health benefits of indigestible carbohydrate polymers as dietary fiber: A review. International Journal of Biological Macromolecules, v.61, p.1-6, 2013.

MELLO, S. C. R. P; SILVA, L. E; S. MANO; FRANCO, R. M. Avaliação bacteriológica e físico-química das carnes do dorso e coxa de rã (ranacatesbeiana) processadas em matadouro comercial. Revista Brasileira de Ciência Veterinária, 2006.

OLIVEIRA, M. D.; SCHMIDT, V. C. R.; Desenvolvimento de empanados aplicando dorso de Rã Touro (Rana catesbeianna). Universidade Federal de Uberlândia, Campus Patos de Minas 2017.

TEIXEIRA, E.; MEINERT, E. M.; BARBETTA, P. A. Métodos sensoriais. In: Análise sensorial de alimentos (pp. 66-119). Florianópolis: Editora da UFSC (1987). 